\title{
CRISPR/Cas9 editing of three CRUCIFERIN C homoeologues alters the seed protein profile in Camelina sativa
}

\author{
Wendy J. Lyzenga ${ }^{1,2}$, Myrtle Harrington², Diana Bekkaoui ${ }^{2}$, Merek Wigness ${ }^{2}$, Dwayne D. Hegedus ${ }^{2,3}$ and
} Kevin L. Rozwadowski ${ }^{*}$ (i)

\begin{abstract}
Background: The oilseed Camelina sativa is grown for a range of applications, including for biofuel, biolubricants, and as a source of omega-3 fatty acids for the aquaculture feed industry. The seed meal co-product is used as a source of protein for animal feed; however, the low value of the meal hinders profitability and more widespread application of camelina. The nutritional quality of the seed meal is largely determined by the abundance of specific seed storage proteins and their amino acid composition. Manipulation of seed storage proteins has been shown to be an effective means for either adjustment of nutritional content of seeds or for enhancing accumulation of high-value recombinant proteins in seeds.

Results: CRISPR/Cas9 gene editing technology was used to generate deletions in the first exon of the three homoeologous genes encoding the seed storage protein CRUCIFERIN C (CSCRUC), creating an identical premature stop-codon in each and resulting in a CSCRUC knockout line. The mutant alleles were detected by applying a droplet digital PCR drop-off assay. The quantitative nature of this technique is particularly valuable when applied to polyploid species because it can accurately determine the number of mutated alleles in a gene family. Loss of CRUC protein did not alter total seed protein content; however, the abundance of other cruciferin isoforms and other seed storage proteins was altered. Consequently, seed amino acid content was significantly changed with an increase in the proportion of alanine, cysteine and proline, and decrease of isoleucine, tyrosine and valine. CSCRUC knockout seeds did not have changed total oil content, but the fatty acid profile was significantly altered with increased relative abundance of all saturated fatty acids.
\end{abstract}

Conclusions: This study demonstrates the plasticity of the camelina seed proteome and establishes a CRUC-devoid line, providing a framework for modifying camelina seed protein composition. The results also illustrate a possible link between the composition of the seed proteome and fatty acid profile.

Keywords: CRISPR/Cas9, Camelina, Gene editing, Mutation detection, Drop-off assay, Droplet digital PCR, Seed storage protein, Cruciferin, Proteome rebalancing, Amino acid content, Fatty acid profile

\section{Background}

Camelina sativa (camelina) is an under-exploited Brassicaceae oilseed crop that has received renewed interest due to a favourable blend of agronomic properties, a high seed oil content (30-49\%) with unique composition, and amenability to genetic manipulation and improvement [1]. Initial

\footnotetext{
* Correspondence: Kevin.Rozwadowski@Canada.ca

${ }^{2}$ Agriculture and Agri-Food Canada, 107 Science Place, Saskatoon, SK S7N 0X2, Canada

Full list of author information is available at the end of the article
}

efforts in camelina were driven by its potential as a biodiesel feedstock requiring low-input for production [2,3]. Accordingly, the fatty acid profile of camelina seed oil has been engineered for elevated oleic acid content [4-6]. In addition, the high omega-3 (alpha-linolenic acid, 30-43\%) content of camelina oil holds potential as a terrestrial replacement for fish oil in aquaculture [1, 7-9]. Correspondingly, camelina has been used for the production of the omega-3 fish oils eicosapentaenoic acid and docosahexaenoic acid [10, 11]. Similar to other oilseed crops, the seed

(c) The Author(s). 2019 Open Access This article is distributed under the terms of the Creative Commons Attribution 4.0 International License (http://creativecommons.org/licenses/by/4.0/), which permits unrestricted use, distribution, and reproduction in any medium, provided you give appropriate credit to the original author(s) and the source, provide a link to the Creative Commons license, and indicate if changes were made. The Creative Commons Public Domain Dedication waiver (http://creativecommons.org/publicdomain/zero/1.0/) applies to the data made available in this article, unless otherwise stated. 
meal remaining after oil extraction is considered a coproduct. Camelina seed protein content (20-29\%) results in a rich meal that combined with its relatively low levels of glucosinolates makes it attractive for livestock and aquaculture feed [1]. However, tailoring of the quality and content of the seed meal is important for improving the economic competitiveness of camelina oil and thereby increasing the sustainability and profitability of camelina production and processing [12-15].

Seed meal is largely composed of seed storage proteins that serve as a nutrient resource during early seedling development [16]. During seed maturation, carbon and nitrogen resources are largely directed toward production of these highly abundant proteins $[16,17]$. The relative abundance and amino acid content of different seed storage proteins influence the nutritional quality and economic value of the seed meal [13]. Manipulation of seed storage proteins is an area of interest in a number of plant species for improvement of nutrient composition and to express foreign proteins [15, 18-22]. Such efforts are largely constrained by the inherent metabolic programming directing production of endogenous seed storage proteins $[17,19]$. Reduction of seed storage proteins using gene knock-out or knock-down approaches has been effective in by-passing these limits and increasing foreign protein yield in soybean [19], Arabidopsis [23] and rice [21, 24] by making available metabolic resources originally monopolized by endogenous seed storage protein synthesis.

The cruciferins (legumin-type globulins; 11S or 12S) and napins (napin-type albumins; $2 \mathrm{~S}$ ) are the predominant classes of seed storage proteins in the Brassicaceae [13]. In camelina, $60 \%$ of seed meal protein is composed of cruciferins [25], thus altering cruciferin abundance is a key target for modulating meal protein composition. The genome sequence of C. sativa [26] possesses 12 genes encoding cruciferins that are classified into four families (A, B, C, and D) [27]. In this study, a CsCRUC knockout line was generated using CRISPR/Cas9 gene editing to provide a platform for investigating CRUC effects on the camelina seed proteome.

CRISPR/Cas9 is rapidly transforming genetic studies in crop species because of its specificity, ease of use, and ability to generate novel alleles $[28,29]$. In this system, the Cas9 endonuclease binds to a single guide RNA (gRNA), which directs the complex to the genomic target locus with homology to the 20 base pair programmable spacer region of the gRNA [30]. The resulting DNA doublestranded break may be repaired through non-homologous end joining (NHEJ) or homology-directed repair (HDR) mechanisms. Error-prone repair through NHEJ tends to generate insertions or deletions (indels) at the targeted locus, which can alter the reading frame and create functionally null knockout alleles through formation of non- sense mutations leading to truncated and non-functional proteins. HDR has the potential to make prescribed substitutions and generate specific edits based on the sequence of the repair template [31]. CRISPR/Cas9 gene editing has been deployed in a variety of plant species and, recently, in camelina $[5,6,32]$.

Similar to many crops, C. sativa is polyploid and is composed of three highly undifferentiated sub-genomes [26]. Often, mutations in each homoeologue from all three subgenomes (G1, G2, G3), totalling six mutated homoeoalleles, are required to manifest a phenotype; in other cases where gene dosage is a factor, mutations in only one or two homoeoalleles may be necessary [5]. Conventional methods for detecting CRISPR/Cas9-mediated mutations are not well-suited for polyploids as these methods are not quantitative. In this study, a droplet digital PCR (ddPCR) method $[33,34]$ was applied to detect heritably stable progenitor mutations and to precisely determine the number of CRISPR/Cas9-mediated mutant alleles and wild-type alleles present in camelina lines. Using this ddPCR drop-off assay, a complete CsCRUC knockout line was identified with all six homoeoalleles mutated. Consistent with the proteome rebalancing theory [17], the loss of CRUC did not alter total seed protein content, but did alter the composition of the seed protein profile and levels of some amino acids, as well as several fatty acids. This CsCRUC knockout line provides a means to assess the effects of loss of CRUC on the seed proteome and seed composition, and also provides a platform for investigating the directed manipulation of seed meal protein composition.

\section{Results \\ Design of the CsCRUC gRNA spacer sequence and CRISPR/Cas9 construct}

The $C$. sativa genome sequence encodes three homoeologues of CRUCIFERIN C (CRUC), which correspond to its three sub-genomes (CsCRUC-G1, CsCRUC-G2, and CsC RUC-G3; for gene identifiers see Fig. 1a) [26]. Similarly, the C. sativa genome contains three homoeologues of $C R U C I-$ FERIN B (CsCRUB-G1, CsCRUB-G2, and CsCRUB-G3) with directly adjacent homoeologues of CRUCIFERIN D (CsCRUD-G1, CsCRUD-G2, and CsCRUD-G3), as found in Arabidopsis thaliana [35-37]. Three genes also encode CRUCIFERIN A: two paralogues on G1 (CsCRUA1-G1, CsCRUA2-G1), and one homoeologue on G3 (CsCRUAG3); there is no G2 member. This study focused on the CRUC homoeologues as this group has the most abundant transcript of the gene family [38] (Additional file 1: Figure S1), as observed in Arabidopsis [36], and is the most divergent at the amino acid level [37, 39], thereby making elimination of CRUC a good target for altering camelina seed protein and amino acid composition. Additionally, CRUC has unique structural and physico-chemical properties, and 


\section{a \\ CsCRUA1 G1 Csa11g070580 CsCRUA2 G1 Csa11g070590 CSCRUA G2 Csa18g009670 CsCRUB G1 Csa17g006950 CSCRUB G2 Csa14g004960 CsCRUB G3 Csa03g005050 CSCRUC G1 Csa11g015240 CSCRUC G2 Csa10g014100 CSCRUC G3 Csa12g021990 CSCRUD G1 Csa17g006960 CSCRUD G2 Csa14g004970 CsCRUD G3 Csa03g005060}

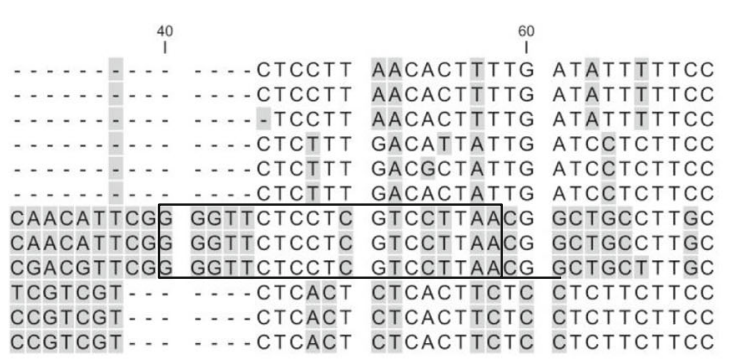

gRNA512
160

CGAGCCGTCA CACGTACTGA AGAGTGAGGC CGAGCCATCA CACGTACTGA AGAGTGAGGC CGAGCCATCA CACGTACTGA AGAGTGAGGC CGAACCGTCT CAAGTAATCC AGAGCGAGGG CGAACCGTCG CAAGTAATCC AGAGCGAGGG CGAACCGTCT CAAGTAATCC AGAGCGAGGG TGAAGCCACC GAAACTATCA AAAGTGAGGC TGAAGCCACC GAAACTATCA AAAGTGAGGC TGAAGCCACC GAAACTATCA AAAGTGAGGC CGCTCCAGCC CAAGCGACCA AGTTTGAAGC CGCTCCAGCC CAGGCAACCA AGTTTGAAGC CGCTCCAGCC CAGGCAACCA AGTTTGAAGC

b

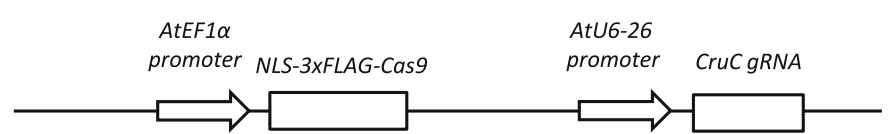

Fig. 1 Specificity of CSCRUC gRNA spacer design and schematic of CRISPR/Cas9 construct. a Partial sequence alignment of the first exon from CSCRUA, CSCRUB, CSCRUC, and CSCRUD gene families. The CSCRUC gRNA spacer sequences (gRNA512 and gRNA510) used in this study are boxed with the PAM sequence underlined. Numbers indicate nucleotide position from the start codon and shading indicates differences in nucleotide sequence. $\mathbf{b}$ Schematic of the CRIPSR/Cas9 construct. Expression of Cas9 is under control of the AtEFla promoter and encodes a nuclear localization signal (NLS) at the N- and C-termini, plus a 3xFLAG epitope tag. The AtU6-26 promoter drives expression of the CsCRUC sgRNA cassette. Construct is not represented to scale

reduced bioaccessibility [39, 40]; thus, its elimination may significantly affect camelina seed meal quality and utility.

The sequence of the first exon of the CRUCIFERIN genes was aligned and searched for potential gRNA spacer sequences that would be specific to CsCRUC-G1, CsCRUCG2, and CsCRUC-G3, based upon uniqueness of the requisite protospacer adjacent motif (PAM) sequence and mismatches or indels vs. the other cruciferin genes (Fig. 1a). A gRNA spacer sequence (gRNA-512) that anneals to the transcribed strand and one gRNA spacer sequence (gRNA510) targeting the non-transcribed strand (Fig. 1a) were selected. An Arabidopsis RNA polymerase III-dependent promoter derived from AtU6-26 encoding a member of the spliceosome complex was used for expressing the gRNA cassette (Fig. 1b; Additional file 13 [41]). Due to its high expression in rapidly growing tissues, including meristems and developing gametophytes, the Arabidopsis EF1 $\alpha$ promoter [42] was used to express Cas9 codon optimised for expression in crucifers (Additional file 14). Transgenic lines with gRNA512 or gRNA510 and Cas 9 were generated by floral dip [43], and screened for transformants using glufosinate herbicide selection. $\mathrm{T}_{1}$ lines were selected for further evaluation based on expression of the Cas 9 transgene (gRNA512-line 1, gRNA512-line 13, gRNA510-line 7 and gRNA510-line 9).

\section{Design and validation of droplet digital PCR drop-off assay}

A ddPCR [44] drop-off assay [33, 34] was applied to detect CRISPR/Cas9-mediated mutations in CsCRUC. A duplex primer probe assay was designed consisting of a drop-off probe (FAM fluorophore) that binds only to the wild-type gRNA annealing site and a reference probe
(HEX fluorophore) that binds 150-200 base pairs away from the predicted Cas9 cut site (Fig. 2a). With wildtype DNA both probes will bind resulting in doublepositive droplets presenting both fluorescent signals (Fig. 2b). In the event of a CRISPR/Cas9-mediated mutation the drop-off probe (FAM) will no longer bind, resulting in single-positive (HEX) droplets indicative of a mutated allele (Fig. 2b). Because ddPCR is an absolute quantification assay, the number of wild-type and mutated allele sequences can be determined based on the fractional abundance of reference probe events and drop-off probe events (Fig. 2c).

Probe and primer assays for the predicted Cas 9 cut sites based on both gRNA510 and gRNA512 were validated using synthesized DNA cassettes containing either wild type CsCRUC sequence or a 4-base deletion $\left(C s C R U C^{\Delta 4}\right)$ at the predicted Cas 9 cut site (Fig. $2 \mathrm{~b}$ and Additional file 2: Figure S2). As expected, wild type CsCRUC generated double-positive droplets with signals for both the drop-off probe and reference probes, whereas CsCRUC ${ }^{\Delta 4}$ generated single-positive droplets with signal for only the reference probe. A mixture of both CsCRUC and $C s C R U C^{\Delta 4}$ casssettes generated both double-positive and singlepositive droplets. As predicted, no droplets were positive for only the drop-off probe.

\section{Detection of CRISPR/Cas9 mediated mutations in CSCRUC in the $\mathrm{T}_{2}$ generation}

To identify plant lines with heritable mutations in CsCRUC we screened the $T_{2}$ generation instead of the $T_{1}$ generation. The ddPCR drop-off analysis using wild-type genomic DNA solely displayed the expected double-positive signals (Fig. 3a). Twenty of the $85 \mathrm{~T}_{2}$ plants evaluated from 


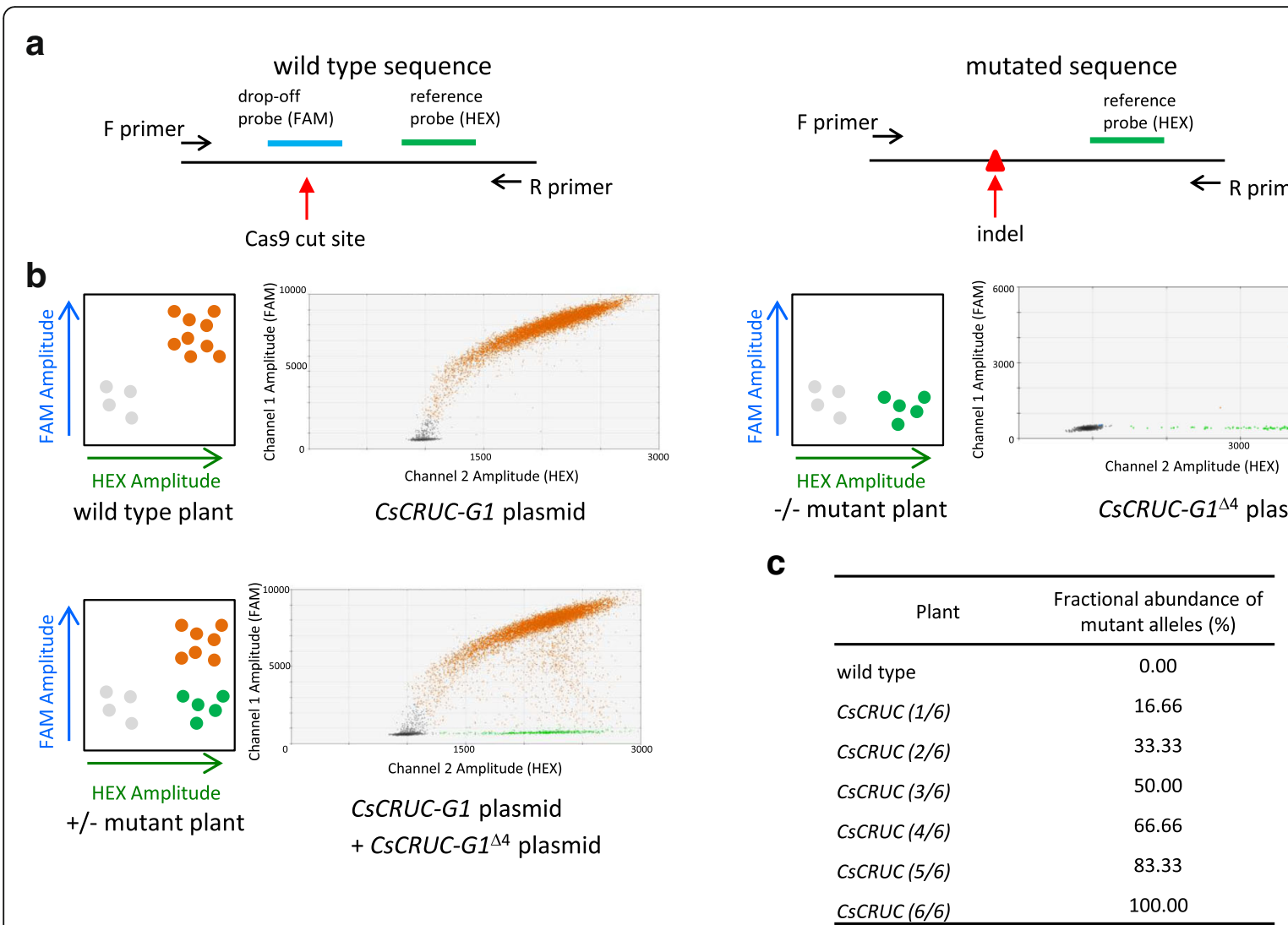

Fig. 2 Overview and validation of ddPCR drop-off assay to detect CRISPR/Cas9-mediated mutations. a Schematic of probe and primer configuration for detection of mutations. Both the drop-off probe (FAM) and reference probe (HEX) bind to the same amplicons derived from wild-type sequences. Sequence polymorphisms prevent binding of the drop-off probe and only the reference probe binds to amplicons with mutations at the Cas9 cut site. $\mathbf{b}$ Schematic of anticipated drop-off assay outcome represented on a 2-D fluorescence intensity plot and results using synthesized CSCRUC-G1 plasmid template. Wild type plants or CSCRUC-G1 plasmid generate amplicons in which both drop-off probe and reference probe bind, generating only double-positive (HEX and FAM) droplets. Mutant plants with no wild-type sequence or CSCRUC-G1 ${ }^{\Delta 4}$ plasmid containing a four base pair deletion at the predicted Cas9 cut site generate amplicons in which only the reference probe binds, resulting in only single-positive (HEX) droplets. Plants with wild-type sequence and mutated sequence or a mixture of CsCRUC-G1 plasmid and CsCRUCG1 ${ }^{\Delta 4}$ plasmid generate wild-type amplicons in which both drop-off probe and reference probe bind, generating double-positive droplets, and mutation-containing amplicons in which only the reference probe binds, generating single-positive droplets. c Expected fractional abundance of drop-off probe events vs. reference probe events representing when heritable mutations have occurred in one to six alleles of CsCRUC

gRNA512-1 and 11 of the $85 \mathrm{~T}_{2}$ plants from gRNA512-13 displayed single-positive droplets, indicative of mutations at the predicted Cas9 cut site (Fig. 3a and Table 1). The dropoff assay enabled estimation of the number of mutant alleles in these plants (Fig. 3b, c). The majority contained only one mutated allele $(\sim 16 \%$ fractional abundance of mutant alleles). Two plants were detected with two mutated alleles ( 33\% fractional abundance of mutant alleles); these plants were designated gRNA512-1-69 and gRNA512-137 (Fig. 3a; Table 1). Screening of $90 \mathrm{~T}_{2}$ progeny plants from each of gRNA510-7 and gRNA510-9 failed to detect any plants with mutations; material from these lines was not analysed further. To verify the drop-off assay results and to investigate the nature of mutations generated by gRNA512, CsCRUC gene sequences were amplified by PCR, cloned and sequenced from four gRNA512-1 and five gRNA51213 derived $\mathrm{T}_{2}$ plants identified as possessing mutations by the drop-off assay. Approximately 30 cloned amplicons per plant were sequenced (Additional file 3: Figure S3). The majority of mutations across plant lines were single basepair deletions (Table 1). Consistent with the results from the ddPCR drop-off assay, the plants identified with two mutated alleles (gRNA512-1-69 and gRNA512-13-7) in the initial population screen were confirmed to contain two mutant CsCRUC alleles (Table 1 and Additional file 3: Figure S3). Line gRNA512-1-69 contains an identical single base pair deletion in both a CsCRUC-G1 and CsCRUC-G3 allele (gRNA512-1-69 wt/-1, wt/wt, wt/-1 $^{\text {) }}$ and was selected for further investigation.

\section{Screening for CRISPR/Cas9 mediated mutations in CsCRUC in the $T_{3}, T_{4}$, and $T_{5}$ generation}

The gRNA512-1-69 ${ }^{\mathrm{wt} /-1}$, wt/wt, wt/-1 line retained the CRISPR/Cas9 transgene, as determined by detecting Cas 9 


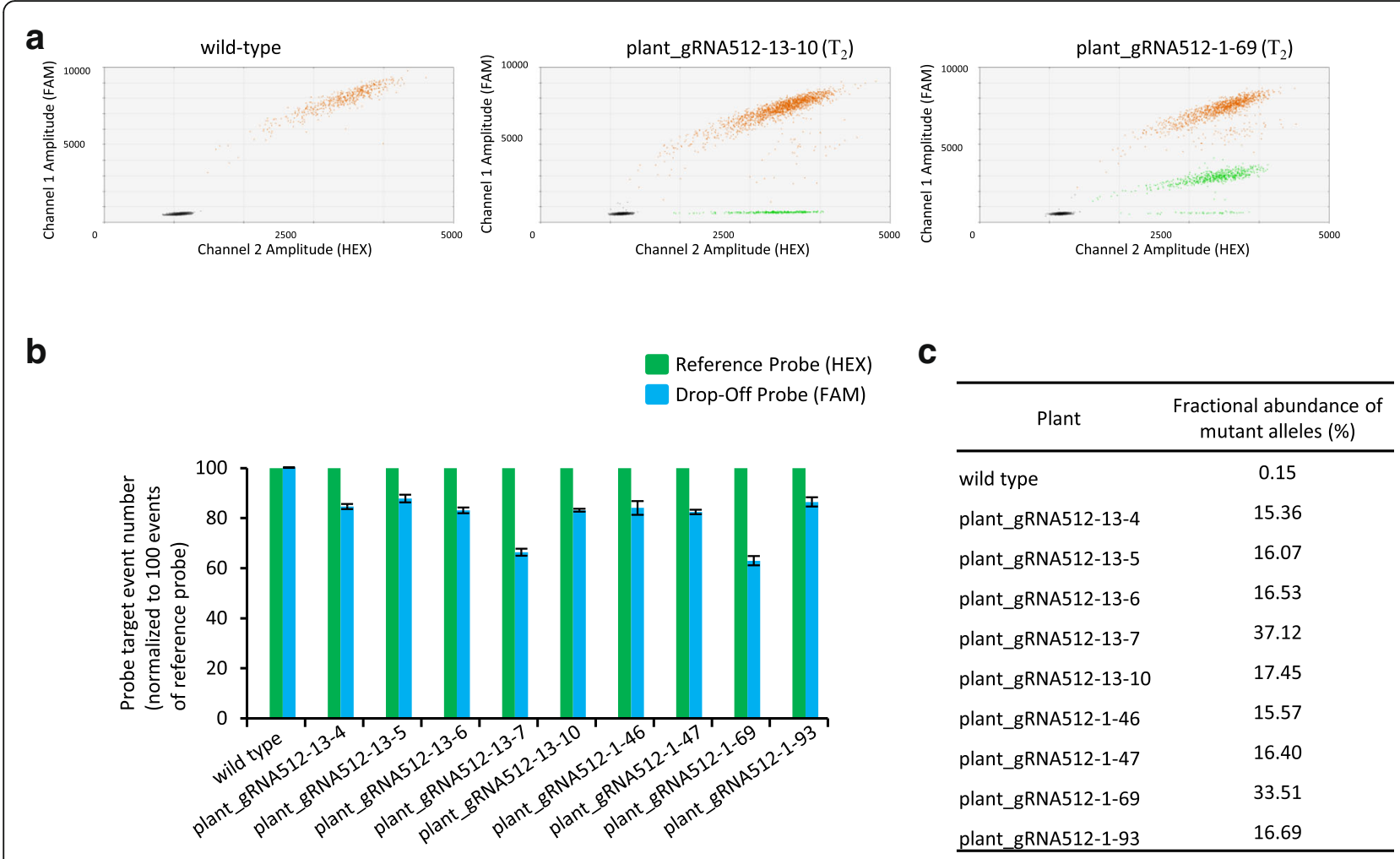

Fig. 3 Detection of CSCRUC alleles with CRISPR-mediated mutations in $T_{2}$ generation plant lines using a ddPCR drop-off assay. a Fluorescence intensity plot from wild type camelina displaying double-positive droplets for both the drop-off probe (FAM) and reference probe (HEX). Plant_gRNA512-13-10 and plant_gRNA512-1-69 are representative lines containing CRISPR-mediated mutations and generate droplets that are double-positive (FAM and HEX) and droplets that are single-positive (HEX). b Quantification of drop-off probe events and reference probe events in wild type and nine $T_{2}$ plants containing mutations. Probe targets are normalized to 100 reference probe events. Values are an average of three replicates \pm S.D. Differences between expected reference probe events and observed reference probe events were assessed using a chi-square test. c Fractional abundance (\%) of mutated alleles from b

using PCR, and was propagated to the $\mathrm{T}_{5}$ generation in order to identify a line with six mutated CRUC alleles. Using the drop-off assay we screened $\mathrm{T}_{3}, \mathrm{~T}_{4}$ and $\mathrm{T}_{5}$ generation plants and identified lines gRNA512-1-69-8 (4/6 mutated alleles), gRNA512-1-69-8-7 (5/6 mutated alleles), and gRNA512-1-69-8-7-11 (6/6 mutated alleles), respectively (Fig. 4). The CsCRUC alleles in representative lines were amplified by PCR, cloned and sequenced, revealing an identical single base pair deletion in the mutated CsCRUC alleles (Table 1, Fig. S3). The genotype gRNA 512-1-69-8-7 - 11 $1 /-1,-1 /-1,-1 /-1$ is hereafter referred to as CsCRUC $C^{-1-,-/-,-/-}$.

\section{Analysis of protein and amino acid profile of CsCRUC knockout seeds}

The CsCRUC $C^{-1,-,-,-/-}$ line contains a single base pair deletion at nucleotide 53 of the open reading frame of each homoeologue generating a premature stop codon at codon 42 (Additional file 7: Table S1). Under the same growing conditions, wild-type and $C s C R U C^{-1-,-1-,-/-}$ plants did not exhibit noticeable differences in growth and development. Seed weight was found not to significantly differ between the genotypes (Table 2). For seed protein extracts, neither the soluble protein content of wild-type and CsCRUC $C^{-/-,-/,-/-}$, as determined using a Qubit assay, nor the total protein content, as determined by nitrogen content analysis (\% N) of defatted seed meal, was found to be significantly different (Table 2). These results demonstrate inactivation of CsCRUC does not impact overall protein content and suggests that abundance of other seed storage proteins is likely elevated to maintain overall protein content in the CsCRUC $C^{-/,-1-,-1-}$ seeds.

Cruciferins are synthesized as preproteins that are cleaved into $\alpha$ and $\beta$ chains linked by a disulfide bond to form protomers, three of which combine into the final hexameric structures [13]. SDS-PAGE analysis of seed protein extracts under non-reducing conditions typically display an abundant $48-56 \mathrm{kDa}$ band, characteristic of cruciferin protomers that resolve under reducing conditions as a cluster of $\alpha$ chain $(29-34 \mathrm{kDa})$ and $\beta$ chain (20$23 \mathrm{kDa}$ ) protein bands [13, 25, 39]. Tris-Glycine-extended (TGX)-gel analysis was used to determine if the pattern of soluble protein content was altered in CsCRUC $C^{-1-,-1-,-/-}$ seeds. Both the wild-type and the CsCRUC $C^{-1-,-1-,-/-}$ seed 
Table 1 CSCRUC allele sequences

\begin{tabular}{|c|c|c|c|}
\hline Plant & Gene* & Gene sequence $^{\dagger}$ & InDel \\
\hline wild type & $\begin{array}{l}\text { CSCRUC G1 } \\
\text { Csa11g015240 }\end{array}$ & $\begin{array}{l}\text { GGGTTCTCCTCGTCCTTAACGGCTGCCTTGCG } \\
\text { AGGCAATCTCTTGGGGTTCCTCCTCAACTAC }\end{array}$ & \\
\hline wild type & $\begin{array}{l}\text { CsCRUC G2 } \\
\text { Csalog014100 }\end{array}$ & $\begin{array}{l}\text { GGGTTCTCCTCGTCCTTAACGGCTGCCTTGCG } \\
\text { AGGCAATCTCTTGGGGTTCCTCCTCAGCTAC }\end{array}$ & \\
\hline wild type & $\begin{array}{l}\text { CsCRUC G3 } \\
\text { Csa12g021990 }\end{array}$ & $\begin{array}{l}\text { GGGTTCTCCTCGTCCTTAACGGCTGCTTTGCG } \\
\text { AGGCAATCTCTTCGGGTTCCTCCTCAGTTAC }\end{array}$ & \\
\hline \multicolumn{4}{|l|}{ T2 generation } \\
\hline plant_gRNA512-13-4 & CSCRUC_G2 $-1+$ & $\begin{array}{l}\text { GGGTTCTCCTCGTCC-TAACGGCTGCCTTGCG } \\
\text { AGGCAATCTCTTGGGGTTCCTCCTCAGCTAC }\end{array}$ & -1 \\
\hline plant_gRNA512-13-5 & CSCRUC_G3 $-1+$ & $\begin{array}{l}\text { GGGTTCTCCTCGTC-TTAACGGCTGCTTTGCG } \\
\text { AGGCAATCTCTTCGGGTTCCTCCTCAGTTAC }\end{array}$ & -1 \\
\hline plant_gRNA512-13-6 & CSCRUC_GI $-/+$ & $\begin{array}{l}\text { GGGTTCTCCTCGTCC-TAACGGCTGCCTTGCG } \\
\text { AGGCAATCTCTTGGGGTTCCTCCTCAACTAC }\end{array}$ & -1 \\
\hline \multirow{2}{*}{ plant_gRNA512-13-7 } & CSCRUC_GI $-/+$ & $\begin{array}{l}\text { GGGTTCTCCTCGTCCTTTAACGGCTGCCTTGCG } \\
\text { AGGCAATCTCTTGGGGTTCCTCCTCAACTAC }\end{array}$ & +1 \\
\hline & CSCRUC_G2 $-1+$ & $\begin{array}{l}\text { GGGTTCTCCTCGTCC-TAACGGCTGCCTTGCG } \\
\text { AGGCAATCTCTTGGGGTTCCTCCTCAGCTAC }\end{array}$ & -1 \\
\hline plant_gRNA512-13-10 & CSCRUC_GI $-/+$ & $\begin{array}{l}\text { GGGTTCTCCTCGT---TAACGGCTGCCTTGCG } \\
\text { AGGCAATCTCTTGGGGTTCCTCCTCAACTAC }\end{array}$ & -3 \\
\hline plant_gRNA512-1-46 & CSCRUC_GI $-/+$ & $\begin{array}{l}\text { GGGTTCTCCTCGTCCTATAACGGCTGCCTTGCG } \\
\text { AGGCAATCTCTTGGGTTCCTCCTCAACTAC }\end{array}$ & +1 \\
\hline plant_gRNA512-1-47 & CSCRUC_G2 - /+ & $\begin{array}{l}\text { GGGTTCTCCTCGTCCTATAACGGCTGCCTTGCG } \\
\text { AGGCAATCTCTTGGGGTTCCTCCTCAGCTAC }\end{array}$ & +1 \\
\hline \multirow{2}{*}{ plant_gRNA512-1-69 } & CSCRUC_GI $-/+$ & $\begin{array}{l}\text { GGGTTCTCCTCGTCC-TAACGGCTGCCTTGCG } \\
\text { AGGCAATCTCTTGGGGTTCCTCCTCAACTAC }\end{array}$ & -1 \\
\hline & CSCRUC_G3 - /+ & $\begin{array}{l}\text { GGGTTCTCCTCGTCC-TAACGGCTGCTTTGCG } \\
\text { AGGCAATCTCTTCGGGTTCCTCCTCAGTTAC }\end{array}$ & -1 \\
\hline plant_gRNA512-1-93 & CSCRUC_G3 $-1+$ & $\begin{array}{l}\text { GGGTTCTCCTCGTCC-TAACGGCTGCCTTGCG } \\
\text { AGGCAATCTCTTGGGGTCCTCCTCAACTAC }\end{array}$ & -1 \\
\hline \multicolumn{4}{|l|}{ T3 generation } \\
\hline \multirow{2}{*}{$\begin{array}{l}\text { plant_gRNA512-1-69- } \\
8\end{array}$} & CSCRUC_GI -/- & $\begin{array}{l}\text { GGGTTCTCCTCGTCC-TAACGGCTGCCTTGCG } \\
\text { AGGCAATCTCTTGGGGTTCCTCCTCAACTAC }\end{array}$ & -1 \\
\hline & CSCRUC_G3 -/- & $\begin{array}{l}\text { GGGTTCTCCTCGTCC-TAACGGCTGCTTTGCG } \\
\text { AGGCAATCTCTTCGGGTTCCTCCTCAGTTAC }\end{array}$ & -1 \\
\hline \multicolumn{4}{|l|}{ T5 generation } \\
\hline \multirow{3}{*}{$\begin{array}{l}\text { plant_gRNA512-1-69- } \\
8-7-1 \overline{1}\end{array}$} & CSCRUC_GI -/- & $\begin{array}{l}\text { GGGTTCTCCTCGTCC-TAACGGCTGCCTTGCG } \\
\text { AGGCAATCTCTTGGGGTTCCTCCTCAACTAC }\end{array}$ & -1 \\
\hline & CSCRUC_G2 -/- & $\begin{array}{l}\text { GGGTTCTCCTCGTCC-TAACGGCTGCCTTGCG } \\
\text { AGGCAATCTCTTGGGGTTCCTCCTCAGCTAC }\end{array}$ & -1 \\
\hline & CSCRUC_G3 -/- & $\begin{array}{l}\text { GGGTTCTCCTCGTCC-TAACGGCTGCTTTGCG } \\
\text { AGGCAATCTCTTCGGGTTCCTCCTCAGTTAC }\end{array}$ & -1 \\
\hline
\end{tabular}

*Zygosity of plant at CsCRUC homoeologues is indicated with + and -

${ }^{\dagger}$ The predicted Cas9 cut site is highlighted in grey. PAM sequences are underlined and SNPs that distinguish homoeologues are bolded. Nucleotide changes $(+$, insertion; - , deletion) are indicated.

protein extracts displayed the expected cluster of $\alpha$ and $\beta$ chain protein bands under reducing conditions (Fig. 5a) and the characteristic protomer band under non-reducing conditions (Additional file 4: Figure S4a). However, under reducing conditions the CsCRUC $C^{-/,-/-,-/-}$seed protein extract was distinct from wild type by the absence of the highest molecular weight band. This pattern of proteins is consistent with inactivation of CsCRUC by the CRISPR/ Cas9-derived nonsense mutation since the CRUC $\alpha$ chain is the largest among the cruciferins with a predicted molecular weight of $\sim 31.5 \mathrm{kDa}$ being $3-4 \mathrm{kDa}$ greater than the other $\alpha$ chains (Additional file 8: Table S2), and is absent in the knockout line.

To further quantify and characterize the protein pattern of the CsCRUC $C^{--,-1-,-/-}$ line the Experion chip-based microfluidics electrophoresis system was used [45]. The Experion software integrates signals detected for internal standard markers and sample proteins and displays the data as an electropherogram with protein abundance being quantifiable based on peak area; this system has been 


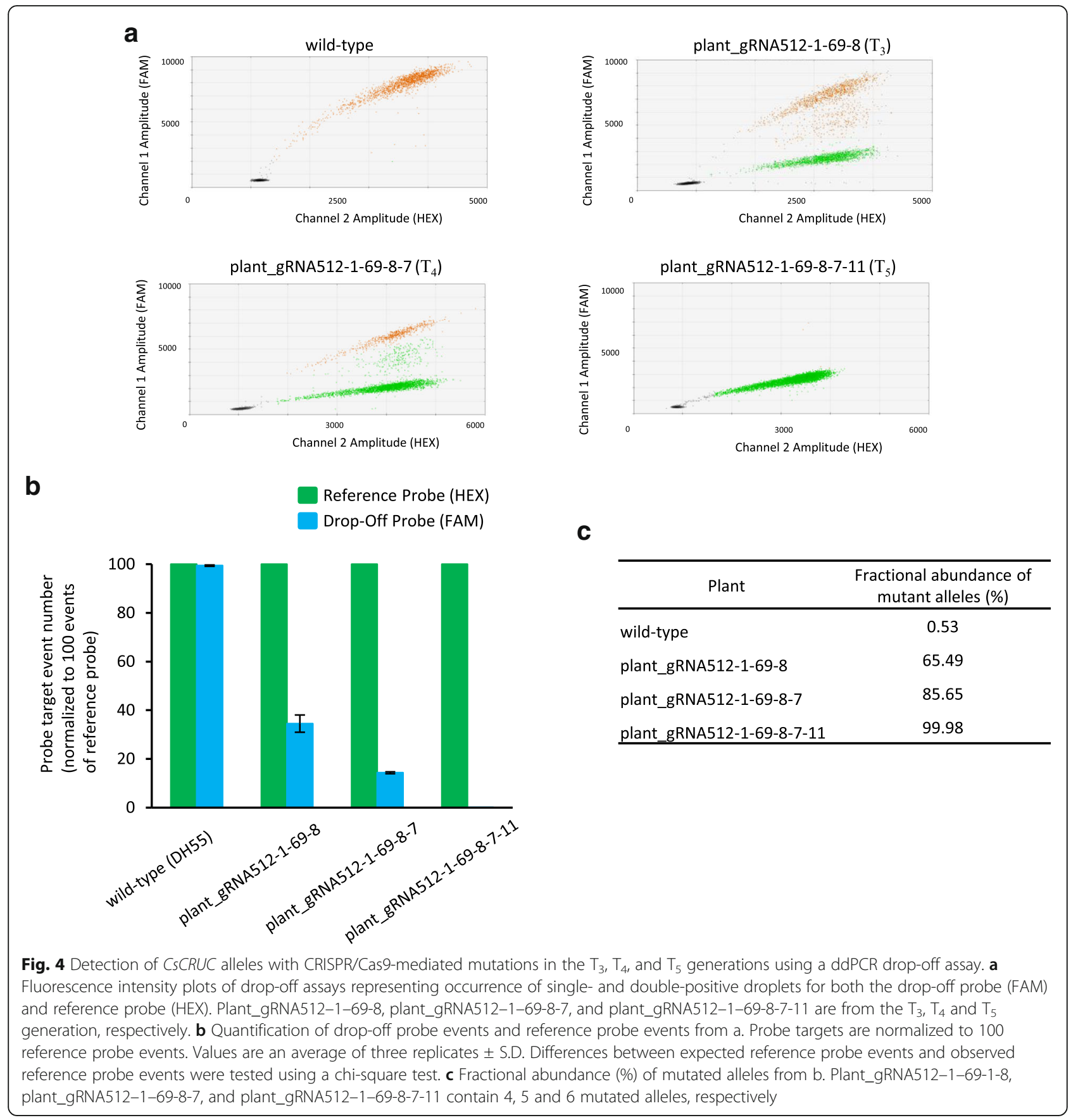

Table 2 Knockout of CSCRUC does not alter seed weight, protein or oil content

\begin{tabular}{|c|c|c|c|c|}
\hline Line & $\begin{array}{l}100 \text { seed weight } \\
(\mathrm{mg})^{\mathrm{a}}\end{array}$ & $\begin{array}{l}\text { protein content (mg/g dry } \\
\text { seed) })^{b}\end{array}$ & $\begin{array}{l}\text { protein content of defatted meal }(\% \mathrm{~N} \\
\text { based) })^{\mathrm{b}}\end{array}$ & $\begin{array}{l}\text { oil content (mg/g dry } \\
\text { seed) }\end{array}$ \\
\hline wild type & $114.3 \pm 1.7$ & $289.24 \pm 9.30$ & $44.01 \pm 0.29$ & $355.33 \pm 5.08$ \\
\hline $\operatorname{Cs} C R \cup C^{1-,-1-,-1-}$ & $105.7 \pm 4.9$ & $306.45 \pm 30.24$ & $44.48 \pm 0.05$ & $364.40 \pm 4.31$ \\
\hline
\end{tabular}

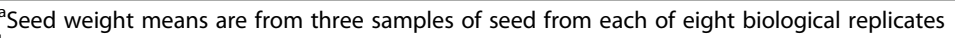

${ }^{b}$ Protein analysis means are from three samples of seed from each of three biological replicates

'Oil analysis means are from one sample of seed from each of five biological replicates

${ }^{\text {a-c }}$ Means of wild-type and CsCRUC $C^{1-,-1,-,-}$ are not significantly different $(p<0.05$, Student's t-test). Means are shown \pm S.E.M
} 


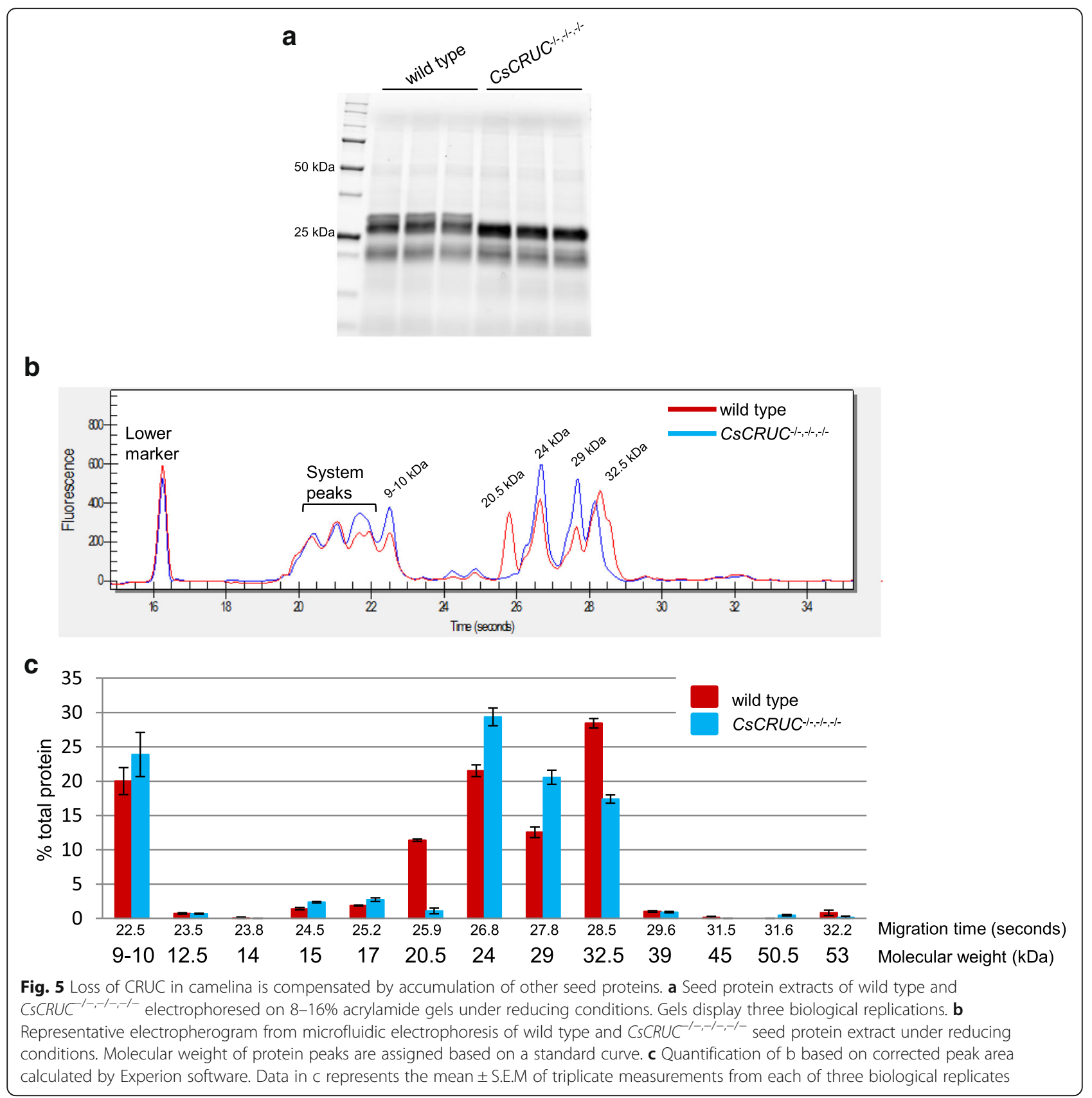

used to evaluate wheat seed storage proteins [46, 47]. Similar to the TGX-gel analysis, the results from microfluidics electrophoresis indicated the protein profile of CsCRUC $C^{-1,--\mid-,-/-}$ seeds was altered compared to wildtype (Fig. 5b, c; Additional file 4: Figure S4b, c). Under reducing conditions, the 48 and $50 \mathrm{kDa}$ protein peaks representative of the cruciferin protomers detected under nondenaturing conditions (Additional file 4: Figure S4b, c) are almost completely eliminated and $\sim 20-32.5 \mathrm{kDa}$ protein peaks appear, which are likely composed of cruciferin $\alpha$ (27.1-31.7 kDa; Additional file 8: Table S2) and $\beta$ (19.8$21.3 \mathrm{kDa}$; Additional file 8: Table S2) chains (Fig. 5b, c).
While some discrepancies exist between the predicted molecular weights based on the electropherogram and molecular weights based on protein sequences (Additional file 8: Table S2), the 29 and $32.5 \mathrm{kDa}$ peaks and the 20.5 and $24 \mathrm{kDa}$ peaks likely represent the cruciferin $\alpha$ and $\beta$ chains, respectively. Although the $\alpha$ chain peaks are not completely resolved in the electropherogram, it is evident that the highest molecular weight shoulder peak, nominally designated as $32.5 \mathrm{kDa}$ (Fig. $5 \mathrm{~b}$ ), is missing in CsCRUC $C^{-1-,--,-1-}$ seeds, as per the TGX gel results, and likely represents the region where the CRUC $\alpha$ chain migrates. Correspondingly, a $29 \mathrm{kDa}$ peak is elevated in 
CsCRUC $C^{-1-,-1-,-/-}$ seeds and is consistent with being composed of $\alpha$ chains from CRUA, B or D (27.1-28.6 kDa; Additional file 8: Table S2). The wild-type seed protein profile also contains a unique peak of $20.5 \mathrm{kDa}$ and an elevated $24 \mathrm{kDa}$ peak, likely representing the highly abundant $\beta$ chains from CRUA, B, C and D (Additional file 8: Table S2). The CsCRUC $C^{-,-,-,-/-}$seed protein profile lacks the $20.5 \mathrm{kDa}$ peak and has an elevated $24 \mathrm{kDa}$ peak. Although the $\beta$ chains have similar molecular weights (19.9-21.3 $\mathrm{kDa}$; Additional file 8: Table S2), CRUC $\beta$ has several residues unique from CRUA, B and D that may confer increased negative charge and increased relative mobility during electrophoresis in the presence of SDS $([48,49]$; Additional file 5: Figure S5). This potential altered mobility combined with the approximately $50 \%$ or greater transcript abundance of CsCRUC vs. CsCRUA, B, and D (Additional file 1: Figure S1) is consistent with the 20.5 $\mathrm{kDa}$ peak representing CRUC $\beta$. In addition to these changes in the subunit peaks, the predicted cruciferin protomers revealed under non-denaturing conditions were also altered (Additional file 4: Figure S4b, c). The predicted CRUC protomers peak $(\sim 50 \mathrm{kDa})$ is decreased in $C s C R U C^{-/,-,-,-1-}$ seed protein extracts while a $48 \mathrm{kDa}$ peak, likely corresponding to the protomers of other cruciferins, is increased (Additional file 4: Figure S4b, c). Notably, the abundance of a $9-10 \mathrm{kDa}$ peak under reducing conditions (Fig. 5b, c) and a $17.5 \mathrm{kDa}$ peak under non-reducing conditions (Additional file 4: Figure S4b, c), which is likely composed of the napin large subunit and the mature napin monomer, respectively (Additional file 9: Table S3), is also increased in CsCRUC $\mathrm{C}^{-/,--/,-,-}$seeds. Collectively, these results demonstrate the CsCRUC $C^{-/,-1-,-1-}$ line has altered abundance of seed storage proteins and that loss of CRUC is compensated by elevated levels of other seed storage proteins.

The redistribution of seed storage protein abundance in the CsCRUC $C^{--,-1-,-/-}$ line may also be reflected in amino acid content. The amino acid content of wild type and CsCRUC $C^{-,-,-,-1-}$ seeds was compared and a significant shift in the relative abundance of some amino acids was observed (Fig. 6). Compared to the other camelina cruciferins, CRUC has the highest content of isoleucine and tyrosine (Additional file 6: Figure S6). Correspondingly, the reduced ratio of CRUC:CRUA,B,D observed in CsCRUC $C^{-1-,-1-,-1-}$ seeds correlates with reduced abundance of isoleucine and tyrosine in these seeds $(-11.8 \%$ and $-6.9 \%$, respectively). Similarly, CRUC has the lowest content of alanine, phenylalanine and serine amongst the cruciferins in camelina, and these amino acids are correspondingly elevated in CsCRUC $C^{-,-,-,--/-}$seeds $(+3.5 \%,+6.4 \%$ and $+4.5 \%$, respectively). For the remaining amino acids with significantly changed abundance, including cysteine $(+7.0 \%)$, proline $(+4.8 \%)$, the combined aspartate and asparagine signals
$(-4.5 \%)$, and valine (-8.2\%), correlation with CRUC levels is less clear. Notably, CRUC has the second highest asparagine content and second lowest proline content of the camelina cruciferins, which considering the high relative level of CsCRUC transcription (Additional file 1: Figure S1) and protein abundance (Fig. 5) can be expected to impact levels of these amino acids in $\operatorname{CsCRUC^{-1,-/,--/}}$ seeds. Additionally, amino acid levels may be affected by the elevated abundance of napins observed in CsCRUC $C^{-1,-/-,-/-}$ seeds. For example, camelina napins have a seven-fold higher average cysteine content $(7.0 \%)$ and $75 \%$ higher average proline content $(9.4 \%)$ than in cruciferins $(1.0 \%$ and $5.3 \%$, respectively; Additional file 10: Table S4). In contrast, napins have 54\% lower combined average asparagine and aspartate content $(4.9 \%)$ and $33 \%$ lower average valine content $(5.1 \%)$ than in cruciferins $(10.7 \%$ and $7.6 \%$, respectively). Thus, the elevated napin levels in $\mathrm{CsCRUC^{--,-l-,-/- }}$ seeds can be predicted to affect total amino acid levels. Collectively, the results reflect a general trend for seed amino acid levels to be influenced by the abundance of CRUC either directly through its inherent amino acid composition or indirectly by its influence on the abundance of other seed proteins.

Seed protein content is strongly related to oil content with oilseeds typically exhibiting an inverse relationship between these two storage reserves [50]. The CsCRUC $C^{-/-,-/,-1-}$ seeds did not have a significant difference in seed oil content versus wild type (Table 2), in accord with the maintenance of normal seed protein content resulting from the redistributed abundance of the remaining classes of seed storage proteins. Fatty acid composition was significantly changed in $\mathrm{CsC}$ $R U C^{-/-,-1-,-/}$ seeds (Fig. 7; Additional file 11: Table S5). All saturated fatty acids detected were increased in relative abundance, including palmitic acid $(16: 0 ;+4 \%)$, stearic acid $(18: 0 ;+34 \%)$, eicosanoic acid $(20: 0 ;+44 \%)$, docosanoic acid $(22: 0 ;+37 \%)$ and tetracosanoic acid (24: $0 ;+10 \%)$. In addition, eicosadienoic acid $(20: 2 ;+8 \%)$, erucic acid $(22: 1 ;+10 \%)$, and docosadienoic acid (22:2: $+12 \%)$ were increased in relative abundance. Only $\alpha$ linolenic acid $(18: 3 ;-4 \%)$ was decreased in relative abundance, and all remaining detected fatty acids exhibited no significant difference from wild type. The results confirm the strong relationship between the seed content of oil and protein storage reserves, and illustrate a possible link between abundance of the different classes of seed storage proteins and seed fatty acid profile.

\section{Discussion}

Utilisation of camelina oil in feed, biofuel or industrial feedstock applications requires increased value of the protein meal co-product to increase the underlying economic feasibility of production. As shown for other crops, this can be achieved through manipulation of seed storage 


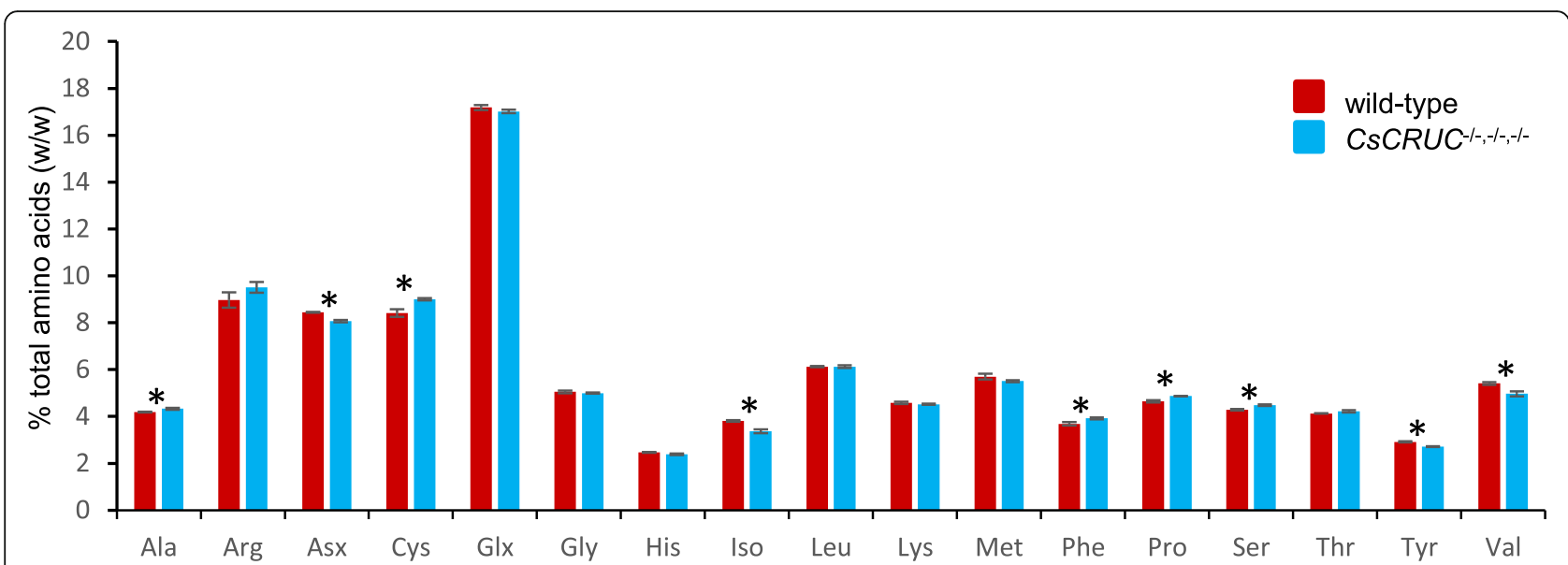

Fig. 6 Seed amino acid composition is altered in CsCRUC knockout line. Means and S.E.M. for percent amino acid (w/w) are shown for triplicate measurements from each of three biological replicates. Glx represents both glutamic acid and glutamine, and Asx represents both aspartic acid and asparagine. Analysis does not include tryptophan. ${ }^{*}$ indicates significant difference between wild-type and CsCRUC ${ }^{1-,-1-,-1-}$ line $(p<0.05$, Student's t-test)

protein constituents to improve desirable amino acid content either by breeding $[18,51-53]$ or by transgenic means to disrupt endogenous seed protein abundance [53-57]. Additionally, seed protein composition can be enhanced by transgenic approaches to express foreign proteins [53], although achieving high yields of foreign proteins in seeds requires reduction of endogenous seed storage proteins $[17,58]$. In this report, we establish a camelina line that can serve as a platform for improving the value of seed meal by deploying CRISPR/Cas9 gene editing to generate a CsCRUC knockout line. CRUC is the most divergent at the amino acid level [37, 39] and is the most highly expressed of the cruciferin gene family [36, 38, 59], which, in combination with its unique physical attributes [39, 40], makes depletion of CRUC a prime means for investigating the potential of manipulating seed storage protein abundance for altering the nutritional value of camelina seed meal. By screening for gene editing events in four generations of a camelina lineage expressing CRISPR components, we identified a line possessing a one base pair deletion at the predicted Cas 9 cut-site in the $5^{\prime}$ region of the first exon of CsCRUC-G1, CsCRUC-G2 and CsCRUC-

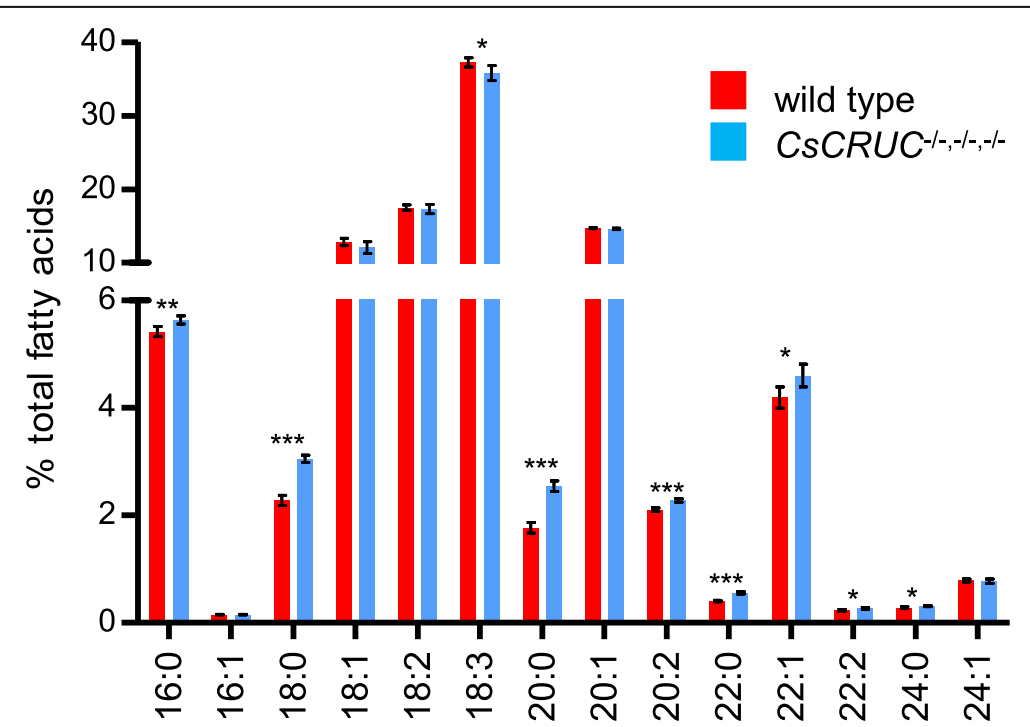

Fig. 7 Seed fatty acid profile is altered in CSCRUC knockout line. Plotted values represent means \pm S.D. for seed samples from five biological replicates. Fatty acids include palmitic acid (16:0), palmitoleic acid (16:1), stearic acid (18:0), oleic acid (18:1, including both delta 9 and delta 11 isomers), linoleic acid (18:2), a-linolenic acid (18:3), eicosanoic acid (20:0), eicosenoic acid (20:1), eicosadienoic acid (20:2), docosanoic acid (22:0), erucic acid (22:1), docosadienoic acid (22:2), tetracosanoic acid (24:0) and nervonic acid (24:1). ${ }^{*}$ indicates significant difference between wild-type and CsCRUC $\mathrm{C}^{-1,-1-,-/-}$ line $(p<0.05$, Student's t-test $)$ 
G3 resulting in frame-shift leading to a premature stop codon in each gene. Seed from a line homozygous for the mutations at all three homoeologues was depleted for CRUC, confirming formation of null alleles. Seed weight and overall total protein content of the CsCRUC knockout seeds were not altered by depletion of CRUC protein; however, the specific protein composition of CsCRUC knockout seeds was altered compared to wildtype, namely the quantity of other cruciferins and napins was increased. This pattern of redistributed seed storage protein abundance without affecting total protein content was also observed in Arabidopsis possessing a T-DNA knockout allele of AtCRC [59], and in camelina and Arabidopsis with RNAi-mediated knockdown of napin leading to elevated cruciferin [27, 39]. These results are consistent with a proteome rebalancing model [17] wherein depletion of one class of seed storage proteins results in a compensatory effect involving elevation of other seed proteins, potentially by the redistribution of metabolic resources amongst the seed storage protein milieu. A previous attempt to knockdown cruciferin levels in camelina using RNAi was not successful [27], making the CsCRUC knockout reported here the first genetic tool to provide insight on the effects of cruciferins on the camelina seed proteome.

Seed meal from the CsCRUC knockout line had significant changes in the level of several amino acids versus wild type. This effect correlated with the altered relative abundance of the seed storage proteins in the knockout line and their respective amino acid composition. In general, amino acids that were most prevalent in CRUC were diminished in seed of the knockout line, and amino acid levels for those most prevalent in the remaining cruciferins or napins were elevated. Interestingly, no significant change in amino acid levels were observed in an Arabidopsis CRUC-deficient line [23], perhaps reflective of a potentially increased capacity for proteome compensation by the other seed storage proteins encoded as multi-gene families in the polyploid camelina. The extent of change in amino acid levels detected in the CsCRUC knockout line was consistent with the range observed by using null alleles of phaseolin in common bean (Phaseolus vulgaris) [52] or of conglycinin and glycinin in soybean [51], providing insight to the scope of change possible through eliminating types of seed storage proteins. Our findings demonstrate the significant impact of the balance of seed proteome constituents and its plasticity on amino acid levels, and point to opportunities to adjust seed meal nutritional value through depletion of one or more seed storage protein genes. The results also outline the potential evolutionary importance of the differential expression of seed storage proteins for camelina [38] and for the related Arabidopsis $[36,59]$ and their relative amino acid composition on establishment of an optimal storage reserve to support germination and seedling establishment.

Seeds from the CsCRUC knockout line did not differ in oil content from wild type, indicating the rebalanced proteome resulting from increased accumulation of other seed storage proteins maintained the relative balance of metabolic resources directed towards oil and protein synthesis during embryo development. These results contrast observations in Arabidopsis CRUCdeficient lines where seed oil content is reported as either being significantly increased [59] or decreased [23], and Arabidopsis lines deficient for combinations of the three cruciferin iosforms where oil content was decreased in all instances [39]. Interestingly, we detected distinct changes in the fatty acid profile of CsCRUC knockout seeds versus wild type with significant increase in the relative abundance of saturated fatty acids. Such changes were not observed in an Arabidopsis CRUC-deficient line [23], perhaps reflective of source-sink differences influencing metabolite availability and utilisation in the polyploid camelina. In general, the altered fatty acid profile reflects a potential subtle alteration in the flux through the fatty acid elongation pathway [60] leading to increased levels of 16:0 through to 24:0 fatty acids. Although the intracellular compartmentalisation of the elongation activities differs for the different classes of fatty acids [60], the process depends on availability of acetyl-CoA. As noted above, the CsCRUC knockout seeds have several changes in total amino acids levels, many of which can be catabolised to form acetyl-CoA [61] and provide a possible substrate for the fatty acid elongation pathway. Thus there may be a link between the seed proteome and oil composition or "oleaome" via sharing of metabolites initially directed towards seed storage protein synthesis. Fatty acid variants accumulate in a temporal fashion during camelina seed development [62] and coincident analysis of these in storage and membrane forms, plus seed storage proteins and free amino acids in future experiments could provide further insight to the relationship between the seed proteome and oleaome.

The polyploid nature of many crop species, including wheat, canola, cotton, and potato, means that gene editingderived mutations often need to be generated and identified in multiple homoeologues for phenotypes to be exhibited [63]. Widely used methods for detecting CRISPR/Cas9 mediated mutations have a number of drawbacks in polyploids. Inexpensive methods, such as nuclease mismatch cleavage assays or restriction length polymorphism assays are not quantitative and are not sufficiently sensitive to resolve the multi-allelic nature of polyploids. In addition, sequencing of PCR-product clones or amplicons is low throughput and non-quantitative. We deployed a droplet digital PCR drop-off assay [33, 34] to detect CRISPR- 
derived mutations in the CsCRUC homoeologues and to track mutated alleles through multiple generations. This application provides a valuable method for detecting heritable gene editing events in polyploid crop species. It also provides a means to quantify the number of mutated alleles in complex plant genomes present in particular lines, which is useful when exploring gene dosage effects.

\section{Conclusions}

The generation and analysis of a CsCRUC knockout line demonstrates the plasticity of the camelina seed proteome and the influence of relative amino acid content and expression levels of seed storage proteins on seed amino acid composition. Alteration of the fatty acid profile in CsCRUC knockout seeds reveals an intriguing link between seed protein and oil composition. The CsCRUC knockout line provides a platform for refining the amino acid and nutritional content of camelina seed meal by combining with other seed storage protein alleles or seed-based expression of foreign proteins. This report also establishes the ddPCR drop-off assay as a highly effective means to identify and track CRISPR-mutated alleles in polyploid genomes and gene families.

\section{Methods}

\section{CRISPR/Cas9 plant transformation constructs}

Plant transformation constructs for expressing CRISPR/ Cas9 components were assembled by multisite Gateway cloning. An open reading frame encoding Cas9 from Streptococcus pyogenes with the nuclear localisation sequence (NLS) from the SV40 large T-antigen followed by the 3xFLAG epitope tag at the N-terminus and the NLS from nucleoplasmin [64] at the C-terminus, a configuration similar to that of [65], was optimised for expression in crucifers by considering codon usage of $A$. thaliana and synthesised by DNA2.0 (Menlo Park, CA, USA). The resulting Cas9optAt cassette (Additional file 14) was subcloned between the Gateway attL1 and attR5 sites leading to pWY454. A cassette flanked by the Gateway attL5 and attL4 sites encoding the AtHSP18.2 (At5g59720) terminator, reported to increase expression of transgenes [66], and hygromycin-resistance cassette was assembled, resulting in pWY457. This plasmid encodes the R6K $\gamma$ origin of replication and can be propagated only in $E$. coli strains expressing the pir gene, a configuration enabling direct selection for recombinants from the multisite Gateway assembly reaction by selecting for hygromycin resistance after transforming a standard $E$. coli strain lacking pir. A gRNA expression cassette (Additional file 13) flanked by the Gateway attR4 and attL2 sites was synthesised (BioBasic, Markham, ON, Canada), termed pET28 + AtU6-26_ gRNA_attR4-L2, comprising $300 \mathrm{bp}$ of the promoter region of AtU6-26 (At3g13855), including the transcription start site [41], and $92 \mathrm{bp}$ of 3' sequence intervened by a lac $Z \alpha$ expression cassette flanked by asymmetric BsaI sites and linked to the gRNA scaffold sequence [67]. CsCRUC gRNA expression cassettes were assembled using the foregoing framework and BsaI-based Golden Gate cloning [68] to introduce a duplex oligonucleotide (Additional file 12: Table S6) encoding the desired spacer sequence, resulting in constructs pMW499 (gRNA510) and pMW501 (gRNA512). The Gateway entry clones pWY454, pWY457 and pMW499 or pMW501 were combined into the plant transformation vector pWY452 by multisite Gateway cloning using LR Clonase II (Thermo Fisher Scientific, Mississauga, ON, Canada), resulting in pMW510 and pMW512 encoding gRNA510 and gRNA512, respectively. pWY452 is a derivative of pWY109 [69] and encodes a $2.6 \mathrm{~kb}$ promoter fragment

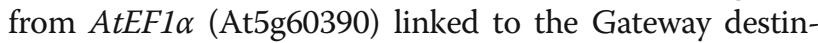
ation cassette followed by the CaMV 35S terminator, plus a lac $Z \alpha$ expression cassette flanked by BsaI sites for Golden Gate cloning, and the PAT gene linked to the EntCUP2 promoter and NOS terminator for selecting transgenic plants. BsaI sites in components used to develop pWY452 were eliminated using site-directed mutagenesis or resynthesised DNA segements (BioBasic) with the remaining two BsaI sites being compatible with the MoClo [70] and GoldenBraid [71] systems.

\section{Generation of transgenic camelina lines}

C. sativa doubled haploid line DH55 [26] (seed provided by Isobel Parkin, Agriculture and Agri-Food Canada, with all permissions obtained) was grown in 6 " pots under growth chamber conditions $\left(19^{\circ} \mathrm{C}\right.$ day and $15^{\circ} \mathrm{C}$ night, $16 \mathrm{~h}$ light and $8 \mathrm{~h}$ dark). The apical shoot from each camelina plant was trimmed at 30-33 days postsowing to encourage lateral bud growth. Soil was supplemented with 20-20-20 fertilizer and plants were treated for powdery mildew and insects with Senator 70WP (thiophanate-methyl; Nippon Soda) and Kontos (spirotetramat; Bayer CropScience), respectively. The constructs pMW510 and pMW512 were transformed into Agrobacterium tumefaciens GV3101 (pMP90) via electroporation. Plants were transformed using the floral dip method [43] with an initial treatment during the early flower bud stage and a second treatment during the full flower bud stage. Immediately after dipping, the plants were kept humid for $24 \mathrm{~h}$. Seeds were harvested after approximately 100 days of growth, then sown on soil and sprayed with glufosinate-ammonium $(1.5 \mathrm{~g} / \mathrm{L})$ on day 7 and day 14. Candidate $T_{1}$ lines were validated using PCR and Cas9optAt (Additional file 14) specific primers (Additional file 12: Table S6). T1 lines and subsequent generations were grown under greenhouse conditions with seasonally supplemented light (16 h light, $8 \mathrm{~h}$ dark) when required, resulting in a generation time of approximately 3 months. 


\section{Reverse transcription ddPCR}

RNA was extracted from young leaves of $T_{1}$ transgenic lines using the RNeasy mini kit (Qiagen) and approximately $800 \mathrm{ng}$ was converted to cDNA using SuperScript $^{\text {ti }}$ III First-Strand Synthesis SuperMix for qRTPCR (Invitrogen), according to instructions by the manufacturer. cDNA was diluted 10-fold and used as template in ddPCR reactions. Hydrolysis probes (generically referred to as TaqMan probes; Integrated DNA Technologies (IDT), Coralville, IA, USA) were used to assess Cas 9 expression with CsPDF2 (Csa17g018660) as an internal standard (Additional file 12: Table S6).

\section{Detection of CRISPR/Cas9-derived mutations in CsCRUC by ddPCR drop-off assay}

The $\mathrm{CsCruC}$ reference and indel detection hydrolysis probes and primers were designed using a combination of the PrimerQuest software (IDT) and the TaqMan Allelic Discrimination option in Primer Express 3.0 software (Applied Biosystems, Foster City, CA, USA). The drop-off probe (FAM) and reference probe (HEX) are approximately 200 base pairs apart and do not contain any SNP amongst the CsCRUC homoeologues. The probe and primer design also took into account sequence similarity between CsCRUA, B, C and $D$ and considered positions of polymorphisms to ensure specificity to CsCRUC. All probe and primer sequences are listed in Additional file 12: Table S6.

To screen plants for CRISPR/Cas9-derived mutations in CsCRUC homoeologues, genomic DNA was extracted from camelina plants using the BioSprint 96 robotic workstation (Qiagen, Valencia, CA, USA) and the BioSprint 96 DNA Plant Kit (Qiagen). Approximately 500 ng of genomic DNA was digested with 5 units of EcoRI for $16 \mathrm{~h}$ then diluted to approximately $5 \mathrm{ng} / \mu \mathrm{l}$. The $25 \mu \mathrm{lddPCR}$ reaction was as follows: $5 \mu \mathrm{M}$ HEX and $5 \mu \mathrm{M}$ FAM TaqMan probe (IDT), $18 \mu \mathrm{M}$ forward and $18 \mu \mathrm{M}$ reverse primer (IDT), $15-25 \mathrm{ng}$ digested genomic DNA or $\sim 10 \mathrm{pg}$ of plasmid containing a $\sim 335$ base pair synthesised cassette (BioBasic, Markham, ON, Canada) of either the wild-type CsCRUC sequence or a four base pair deletion at the predicted Cas9 cut site for gRNA510 or gRNA512 (CsCRUC ${ }^{\Delta 4}$; Additional file 15), $12.5 \mu \mathrm{l}$ of $2 x d d P C R$ Supermix for probes (Bio-Rad, Mississauga, ON, Canada). Droplets were generated using the QX100 Droplet Generator (Bio-Rad), transferred to a clear 96-well PCR plate (Bio-Rad) and sealed with the corresponding adhesive cover, then placed in a Model C1000 thermal cycler (Bio-Rad) with conditions as follows: $95^{\circ} \mathrm{C}$ for $10 \mathrm{~min} ; 35 \mathrm{cycles}$ of $94^{\circ} \mathrm{C}$ for $30 \mathrm{~s}$ and $59^{\circ} \mathrm{C}$ for $30 \mathrm{~s} ; 1$ cycle of $95^{\circ} \mathrm{C}$ for $10 \mathrm{~min}$ and then hold at $4{ }^{\circ} \mathrm{C}$. Droplets were analyzed using a QX100 Droplet Reader or QX200 Droplet Reader (Bio-Rad). The two-dimensional droplet fluorescence intensity plot feature of QuantaSoft software (Bio-Rad) was used to analyse the resulting data. The droplet clusters were grouped using the QuantaSoft lasso threshold adjustment tool.

Camelina lines identified by the drop-off assay had a $480 \mathrm{bp}$ fragment of $\mathrm{CsCruC}$ amplified by PCR using gene specific primers (Additional file 12: Table S6) and Taq polymerase (New England BioLabs, Whitby, ON, Canada) according to the manufacturer's instructions. The resulting PCR product was purified using a QIAquick PCR purification kit (Qiagen), then cloned into pCR4-TOPO using a TOPO TA cloning kit (ThermoFisher). The cloned fragment from approximately 30 clones per plant was amplified by PCR and the amplicons purified using a QIAquick PCR purification kit (Qiagen) and sequenced (National Research Council, Saskatoon, SK, Canada; Eurofins Genomics, Toronto, ON, Canada).

\section{Seed protein extraction and protein content determination}

A CryoMill (Retsch Technology, Haan, Germany) was used to grind seeds (30 seeds per sample; triplicate samples from each of three biological replicates corresponding to seed collected from individual plants of the $T_{6}$ generation) into a fine powder in the presence of liquid nitrogen. Ground seeds were suspended in $1.5 \mathrm{ml}$ seed protein extraction buffer $(100 \mathrm{mM}$ Tris- $\mathrm{HCl}(\mathrm{pH} 7.5), 100 \mathrm{mM}$ $\mathrm{NaCl}, 0.5 \mathrm{M}$ EDTA (pH 8.0), $10 \mathrm{mM}$ AEBSF, $1 \%$ (v/v) Protease Inhibitor Cocktail (Sigma P9599 supplied in DMSO as a proprietary formulation of: AEBSF, Bestatin, E-64, Leupeptin, Pepstatin A, 1,10-Phenanthroline); reduced samples included $10 \mathrm{mM}$ dithiothreitol. Suspensions were centrifuged at $10,600 \mathrm{~g}$ in a microcentrifuge for $20 \mathrm{~min}$ at $4^{\circ} \mathrm{C}$. The supernatant was aliquoted and stored at $80^{\circ} \mathrm{C}$. Protein concentration of seed extracts was determined using a Qubit 2.0 Fluorometer (Thermo Scientific), as per the manufacturer's instructions.

To determine protein content using nitrogen content analysis, mature camelina seeds $(2-3 \mathrm{~g})$ were first defatted via hexane extraction $[72,73]$ by being ground with ball bearings in hexane for $45 \mathrm{~min}$, then filtrated to remove oil and hexanes. Defatted meal was air-dried overnight, then stored at ${ }^{-} 20^{\circ} \mathrm{C}$. Approximately $15 \mathrm{mg}$ samples of ground meal were analysed using the Flash 2000 Organic Elemental Analyzer (Thermo Scientific). A nitrogen to protein conversion factor of 6.25 was used [74]. Three samples of seeds were measured for each of three biological replicates as per above for material from the $\mathrm{T}_{6}$ generation. Significance of differences between wild type and CsCRUC knockout was evaluated using Student's t-test.

\section{Seed protein analysis by gel and microfluidics electrophoresis}

Protein extract samples ( $25 \mathrm{ng}$ ) were loaded on a TGX Stain-Free precast gel (8-16\%; Bio-Rad). Seeds from three individual plants of the $T_{6}$ generation were evaluated. To 
analyse seed protein composition with greater resolution the Experion Automated Electrophoresis system (BioRad) and Experion Pro260 analysis kit were used. Protein samples $(3 \mu \mathrm{g} / \mu \mathrm{l})$ prepared in triplicate from seed samples from each of three individual plants of the $\mathrm{T}_{6}$ generation as per above were treated according to the manufacturer's instructions. In brief, gel solution, gel stain solution, Pro260 ladder and sample buffer were prepared using Experion Pro260 analysis kit reagents; for reducing conditions dithiothreitol was included. The Experion Pro260 chip micro-channels were primed, samples were loaded and then analysed using the Experion system. The resulting electropherograms were analysed using the percentage determination function of the Experion software, which calculates each peak as a percent of the total protein species detected in a sample.

\section{Seed amino acid content quantification}

Amino acid profiles were determined in triplicate for one defatted meal preparation from seed from each of three individual plants of the $\mathrm{T}_{6}$ generation $[75,76]$. Defatted meal prepared for nitrogen content analysis, as described above, was weighed into $10 \mathrm{ml}$ Pyrex screw cap vials with protein equivalents of $5 \mathrm{mg}$ (nitrogen to protein conversion factor of 6.25). Hydrolysis was done in $2 \mathrm{ml}$ of $6 \mathrm{M} \mathrm{HCl}$ (Optima grade, Fisher Scientific) with $1 \%(\mathrm{w} / \mathrm{v})$ phenol for $24 \mathrm{~h}$ at $110^{\circ} \mathrm{C}$, with the exception of cysteine and methionine which were oxidized to cystic acid and methionine sulfone prior to $6 \mathrm{M} \mathrm{HCl}$ acid hydrolysis. Tryptophan was not assessed. DL-2 aminobutyric acid (Sigma-Aldrich) was added as the internal standard to hydrolysates after neutralization with sodium hydroxide at $0.25 \mathrm{mM}$ for $6 \mathrm{M} \mathrm{HCl}$ hydrolysates and $0.2 \mathrm{mM}$ for cystic acid and methionine sulfone hydrolysates. Samples were diluted five-fold with water. Neutralized hydrolysates were filtered using a $0.45 \mu \mathrm{m}$ syringe filter and $2 \mathrm{ml}$ for $6 \mathrm{M} \mathrm{HCl}$ hydrolysates or 2.5 $\mathrm{ml}$ for cystic acid and methionine sulfone hydrolysates applied to an Oasis HLB C18 Cartridge (Waters, Mississauga, ON, Canada), followed by an acetonitrile wash then water added for a final volume of $5 \mathrm{ml}$. Samples were stored at ${ }^{-} 20^{\circ} \mathrm{C}$ prior to pre-column derivatization using the AccQ-Fluor reagent kit (Waters). Separation and quantification of amino acids was performed using high-performance liquid chromatography (Waters Alliance 2695 HPLC, equipped with a Waters 2475 fluorescence detector with excitation wavelength of $250 \mathrm{~nm}$, emission wavelength of $395 \mathrm{~nm}$ and gain of 15). Amino acids were resolved using multistep gradient elution with an injection volume of $5 \mu$ l. Response peaks were recorded with the Empower software (Waters). Significance of differences between wild type and CsCRUC knockout was evaluated using Student's t-test.

\section{Seed oil content and fatty acid profile determination} Seed oil content and fatty acid composition analysis were performed as per Heydarian et al. [77] for seed samples from each of five plants for each genotype. Significance of differences between wild type and CsCRUC knockout was evaluated using Student's t-test.

\section{Additional Files}

Additional file 1: Figure S1. Normalised expression values of the CRUCIFERIN A, B, C and D gene families. (PDF $157 \mathrm{~kb}$ )

Additional file 2: Figure S2. Validation of ddPCR drop-off assay to detect mutations mediated by gRNA512. (PDF $124 \mathrm{~kb}$ )

Additional file 3: Figure S3. CRISPR-derived mutations identified in CsCRUC. (PDF $2911 \mathrm{~kb}$ )

Additional file 4: Figure S4. Electrophoresis under non-denaturing conditions demonstrates loss of CRUC in camelina is compensated by accumulation of other seed proteins. (PDF $108 \mathrm{~kb}$ )

Additional file 5: Figure S5. CsCRUC $\beta$ subunit has unique amino acids that may increase binding of SDS and increase relative mobility during electrophoresis. (PDF $112 \mathrm{~kb}$ )

Additional file 6: Figure S6. Amino acid content of cruciferin A, B, C and D in C. sativa. (PDF $70 \mathrm{~kb}$ )

Additional file 7: Table S1. Translated protein sequence resulting from premature stop codon in CSCRUC knockout alleles. (DOCX $22 \mathrm{~kb}$ )

Additional file 8: Table S2. Predicted molecular weight of camelina cruciferins and derived $a$ and $\beta$ chains. (DOCX $22 \mathrm{~kb}$ )

Additional file 9: Table S3. Predicted total molecular weight of camelina napins and derived small and large subunits. (DOCX $22 \mathrm{~kb}$ )

Additional file 10: Table S4. Amino acid content of camelina cruciferins and napins. (DOCX $23 \mathrm{~kb}$ )

Additional file 11: Table S5. Fatty acid profile of CSCRUC knockout seeds. (DOCX $13 \mathrm{~kb}$ )

Additional file 12: Table S6. Primer, probe and oligonucleotide sequences. (DOCX $23 \mathrm{~kb}$ )

Additional file 13: DNA sequence of gRNA expression cassette. (DOCX $25 \mathrm{~kb}$ )

Additional file 14: DNA sequence of Cas9optAt optimised for general expression in crucifers. (DOCX $27 \mathrm{~kb}$ )

Additional file 15: DNA sequences of synthesised cassettes used to validate drop-off assays. (DOCX $25 \mathrm{~kb}$ )

\section{Abbreviations}

CRISPR: Clustered Regularly Interspaced Short Palindromic Repeats; CRU: CRUCIFERIN; ddPCR: droplet digital polymerase chain reaction

\section{Acknowledgements}

Wen Yang and Tricia Bender contributed to assembly of some of the DNA constructs used in this study, and Anders Keim Wulff-Vester assisted with screening camelina lines for CRISPR-derived mutations in CSCRUC. Rong Zhou performed oil content and fatty acid analysis. The authors thank Sateesh Kagale for critical reading of the manuscript and for contributions to Additional file 1: Figure S1, and Cathy Coutu for assistance with gene annotation and sequence analysis of camelina seed storage proteins.

\section{Authors' contributions}

WJL, MH and DB performed the experiments. MW assembled the DNA constructs. WJL and KLR wrote the manuscript. KLR and DDH conceived the study and coordinated the work. All authors have read and approved the final manuscript. 


\section{Funding}

This research was funded through the Genomics Research and Development Initiative of Agriculture and Agri-Food Canada as awarded to KLR and DDH. The funding agency did not have a role in study design, data collection, analysis or interpretation, or preparation of the manuscript.

\section{Availability of data and materials}

All results and data for this investigation are presented in the enclosed figures and additional files. Materials developd in this study may be obtained from the corresponding author, subject to policies of the author's institution.

\section{Ethics approval and consent to participate}

Not applicable.

\section{Consent for publication}

Not applicable.

\section{Competing interests}

The authors declare that they have no competing interests.

\section{Author details}

${ }^{1}$ Present address: Global Institute for Food Security, University of Saskatchewan, Saskatoon, SK S7N 4J8, Canada. ${ }^{2}$ Agriculture and Agri-Food Canada, 107 Science Place, Saskatoon, SK S7N 0X2, Canada. ${ }^{3}$ Department of Food and Bioproduct Sciences, University of Saskatchewan, Saskatoon, SK S7N 5A8, Canada.

\section{Received: 19 November 2018 Accepted: 5 June 2019}

\section{Published online: 04 July 2019}

\section{References}

1. Vollmann J, Eynck C. Camelina as a sustainable oilseed crop: contributions of plant breeding and genetic engineering. Biotechnol J. 2015;10:525-35.

2. Haslam RP, Sayanova O, Kim HJ, Cahoon EB, Napier JA. Synthetic redesign of plant lipid metabolism. Plant J. 2016;87:76-86.

3. Bansal S, Durrett TP. Camelina sativa: an ideal platform for the metabolic engineering and field production of industrial lipids. Biochimie. 2016:120:9-16.

4. Liu J, Tjellström H, McGlew K, Shaw V, Rice A, Simpson J, Kosma D, Ma W, Yang W, Strawsine M, et al. Field production, purification and analysis of high-oleic acetyl-triacylglycerols from transgenic Camelina sativa. Ind Crop Prod. 2015;65:259-68.

5. Morineau C, Bellec Y, Tellier F, Gissot L, Kelemen Z, Nogue F, Faure JD. Selective gene dosage by CRISPR-Cas9 genome editing in hexaploid Camelina sativa. Plant Biotechnol J. 2016;15:729-39.

6. Jiang WZ, Henry IM, Lynagh PG, Comai L, Cahoon EB, Weeks DP. Significant enhancement of fatty acid composition in seeds of the allohexaploid, Camelina sativa, using CRISPR/Cas9 gene editing. Plant Biotechnol J. 2017; 15:648-57.

7. Hixson SM, Parrish CC. Substitution of fish oil with camelina oil and inclusion of camelina meal in diets fed to Atlantic cod (Gadus morhua) and their effects on growth, tissue lipid classes, and fatty acids. J Anim Sci. 2014; 92:1055-67.

8. Hixson SM, Parrish CC, Anderson DM. Full substitution of fish oil with camelina (Camelina sativa) oil, with partial substitution of fish meal with camelina meal, in diets for farmed Atlantic salmon (Salmo salar) and its effect on tissue lipids and sensory quality. Food Chem. 2014;157:51-61.

9. Napier JA, Usher S, Haslam RP, Ruiz-Lopez N, Sayanova O. Transgenic plants as a sustainable, terrestrial source of fish oils. Eur J Lipid Sci Technol. 2015; 117:1317-24.

10. Petrie JR, Shrestha P, Belide S, Kennedy Y, Lester G, Liu Q, Divi UK, Mulder RJ, Mansour MP, Nichols PD, et al. Metabolic engineering Camelina sativa with fish oil-like levels of DHA. PLoS One. 2014;9:e85061.

11. Ruiz-Lopez N, Haslam RP, Napier JA, Sayanova O. Successful high-level accumulation of fish oil omega-3 long-chain polyunsaturated fatty acids in a transgenic oilseed crop. Plant J. 2014;77:198-208.

12. Herman EM, Schmidt MA. Industrial protein production crops: new needs and new opportunities. GM Crops. 2010;1:2-7.

13. Wanasundara JP. Proteins of Brassicaceae oilseeds and their potential as a plant protein source. Crit Rev Food Sci Nutr. 2011;51:635-77.
14. Popp J, Harangi-Rakos M, Gabnai Z, Balogh P, Antal G, Bai A. Biofuels and their co-products as livestock feed: global economic and environmental implications. Molecules. 2016;21:285.

15. Schmidt MA, Pendarvis K. Proteome rebalancing in transgenic Camelina occurs within the enlarged proteome induced by beta-carotene accumulation and storage protein suppression. Transgenic Res. 2017:26:171-86.

16. Verdier J, Thompson RD. Transcriptional regulation of storage protein synthesis during dicotyledon seed filling. Plant Cell Physiol. 2008:49:1263-71.

17. Herman EM. Soybean seed proteome rebalancing. Front Plant Sci. 2014; 5:437.

18. Gibbon BC, Larkins BA. Molecular genetic approaches to developing quality protein maize. Trends Genet. 2005;21:227-33.

19. Schmidt MA, Herman EM. Proteome rebalancing in soybean seeds can be exploited to enhance foreign protein accumulation. Plant Biotechnol J. 2008;6:832-42.

20. Azevedo RA, Arruda P. High-lysine maize: the key discoveries that have made it possible. Amino Acids. 2010;39(4):979-89.

21. Yang $L$, Hirose $S$, Takahashi H, Kawakatsu T, Takaiwa F. Recombinant protein yield in rice seed is enhanced by specific suppression of endogenous seed proteins at the same deposit site. Plant Biotechnol J. 2012;10:1035-45.

22. Hegedus DD, Baron M, Labbe N, Coutu C, Lydiate D, Lui H, Rozwadowski K. A strategy for targeting recombinant proteins to protein storage vacuoles by fusion to Brassica napus napin in napin-depleted seeds. Protein Expr Purif. 2014;95c:162-8.

23. Lin Y, Pajak A, Marsolais F, McCourt P, Riggs CD. Characterization of a cruciferin deficient mutant of Arabidopsis and its utility for overexpression of foreign proteins in plants. PLoS One. 2013;8:e64980.

24. Tada Y, Utsumi S, Takaiwa F. Foreign gene products can be enhanced by introduction into low storage protein mutants. Plant Biotechnol J. 2003;1: 411-22.

25. Reggiani R, Russo R. Seed protein in Camelina sativa (L.) Crantz var. Calena. Int J Plant Soil Sci. 2015:8(2):1-6.

26. Kagale S, Koh C, Nixon J, Bollina V, Clarke WE, Tuteja R, Spillane C, Robinson SJ, Links MG, Clarke C, et al. The emerging biofuel crop Camelina sativa retains a highly undifferentiated hexaploid genome structure. Nat Commun. 2014:5:3706

27. Nguyen HT, Silva JE, Podicheti R, Macrander J, Yang W, Nazarenus TJ, Nam JW, Jaworski JG, Lu C, Scheffler BE, et al. Camelina seed transcriptome: a tool for meal and oil improvement and translational research. Plant Biotechnol J. 2013:11:759-69.

28. Scheben A, Wolter F, Batley J, Puchta H, Edwards D. Towards CRISPR/Cas crops - bringing together genomics and genome editing. New Phytol. 2017; 216:682-98.

29. Scheben A, Edwards D. Towards a more predictable plant breeding pipeline with CRISPR/Cas-induced allelic series to optimize quantitative and qualitative traits. Curr Opin Plant Biol. 2018;45:1-8.

30. Doudna JA, Charpentier $E$. The new frontier of genome engineering with CRISPR-Cas9. Science. 2014;346:1078.

31. Steinert J, Schiml S, Puchta H. Homology-based double-strand breakinduced genome engineering in plants. Plant Cell Rep. 2016;35:1429-38.

32. Aznar-Moreno JA, Durrett TP. Simultaneous targeting of multiple gene homeologs to alter seed oil production in Camelina sativa. Plant Cell Physiol. 2017:58:1260-7.

33. Findlay SD, Vincent KM, Berman JR, Postovit LM. A digital PCR-based method for efficient and highly specific screening of genome edited cells. PLoS One. 2016;11:e0153901.

34. Mock U, Hauber I, Fehse B. Digital PCR to assess gene-editing frequencies (GEF-dPCR) mediated by designer nucleases. Nat Protoc. 2016;11:598-615.

35. Wan L, Ross ARS, Yang J, Hegedus DD, Kermode AR. Phosphorylation of the 125 globulin cruciferin in wild-type and abi1-1 mutant Arabidopsis thaliana (Thale cress) seeds. Biochem J. 2007:404:247-56.

36. Li Q, Wang BC, Xu Y, Zhu YX. Systematic studies of 125 seed storage protein accumulation and degradation patterns during Arabidopsis seed maturation and early seedling germination stages. J Biochem Mol Biol. 2007:40:373-81

37. Withana-Gamage TS, Hegedus DD, Qiu X, Wanasundara JP. In silico homology modeling to predict functional properties of cruciferin. J Agric Food Chem. 2011:59:12925-38

38. Kagale S, Nixon J, Khedikar Y, Pasha A, Provart NJ, Clarke WE, Bollina V, Robinson SJ, Coutu C, Hegedus DD, et al. The developmental transcriptome atlas of the biofuel crop Camelina sativa. Plant J. 2016;88:879-94. 
39. Withana-Gamage TS, Hegedus DD, Qiu X, Yu P, May T, Lydiate D, Wanasundara JP. Characterization of Arabidopsis thaliana lines with altered seed storage protein profiles using synchrotron-powered FT-IR spectromicroscopy. J Agric Food Chem. 2013;61:901-12.

40. Withana-Gamage TS, Hegedus DD, Qiu X, Wanasundara JP. Solubility, heatinduced gelation and pepsin susceptibility of cruciferin protein as affected by subunit composition. Food Biophys. 2015;10:103-15.

41. Waibel F, Filipowicz W. U6 snRNA genes of Arabidopsis are transcribed by RNA polymerase III but contain the same two upstream promoter elements as RNA polymerase II-transcribed U-snRNA genes. Nucleic Acids Res. 1990;18:3451-8.

42. Curie C, Axelos M, Bardet C, Atanassova R, Chaubet N, Lescure B. Modular organization and development activity of an Arabidopsis thaliana EF-1 alpha gene promoter. Mol Gen Genet. 1993;238:428-36.

43. Lu C, Kang J. Generation of transgenic plants of a potential oilseed crop Camelina sativa by agrobacterium-mediated transformation. Plant Cell Rep. 2008:27:273-8.

44. Hindson CM, Chevillet JR, Briggs HA, Gallichotte EN, Ruf IK, Hindson BJ, Vessella RL, Tewari M. Absolute quantification by droplet digital PCR versus analog real-time PCR. Nat Methods. 2013;10:1003-5.

45. Zhu Z, Lu JJ, Liu S. Protein separation by capillary gel electrophoresis: a review. Anal Chim Acta. 2012:709:21-31.

46. Bradová JME. Comparison of the results of SDS PAGE and chip electrophoresis of wheat storage proteins. Chroma. 2008;67:S83-8.

47. Uthayakumaran S, Batey IL, Wrigley CW. On-the-spot identification of grain variety and wheat-quality type by lab-on-a-chip capillary electrophoresis. J Cereal Sci. 2005;41:371-4.

48. Maley F, Guarino DU. Differential binding of sodium dodecyl sulfate to amino acids as evidenced by elution from Sephadex. Biochem Biophys Res Commun. 1977;77:1425-30

49. Imamura T. Protein-surfactant interactions. In: Somasundaran P, editor. Encyclopedia of surface and colloid science. New York: Taylor \& Francis; 2006. p. 5251-63.

50. Grami B, Stefansson BR, Baker RJ. Genetics of protein and oil content in summer rape: heritability, number of effective factors, and correlations. Can J Plant Sci. 1977;57:937-43.

51. Takahashi M, Uematsu Y, Kashiwaba K, Yagasaki K, Hajika M, Matsunaga R, Komatsu K, Ishimoto M. Accumulation of high levels of free amino acids in soybean seeds through integration of mutations conferring seed protein deficiency. Planta. 2003;217:577-86.

52. Taylor M, Chapman R, Beyaert R, Hernandez-Sebastia C, Marsolais F. Seed storage protein deficiency improves sulfur amino acid content in common bean (Phaseolus vulgaris L.): redirection of sulfur from gamma-glutamyl-Smethyl-cysteine. J Agric Food Chem. 2008;56:5647-54.

53. Galili G, Amir R. Fortifying plants with the essential amino acids lysine and methionine to improve nutritional quality. Plant Biotechnol J. 2013; 11:211-22.

54. Huang S, Frizzi A, Florida CA, Kruger DE, Luethy MH. High lysine and high tryptophan transgenic maize resulting from the reduction of both 19- and 22-kD alpha-zeins. Plant Mol Biol. 2006:61:525-35.

55. Kawakatsu T, Hirose S, Yasuda H, Takaiwa F. Reducing rice seed storage protein accumulation leads to changes in nutrient quality and storage organelle formation. Plant Physiol. 2010;154:1842-54.

56. Sikdar MS, Bowra S, Schmidt D, Dionisio G, Holm PB, Vincze E. Targeted modification of storage protein content resulting in improved amino acid composition of barley grain. Transgenic Res. 2016;25:19-31.

57. Schmidt MA, Barbazuk WB, Sandford M, May G, Song Z, Zhou W, Nikolau BJ, Herman EM. Silencing of soybean seed storage proteins results in a rebalanced protein composition preserving seed protein content without major collateral changes in the metabolome and transcriptome. Plant Physiol. 2011;156:330-45.

58. Lau OS, Sun SS. Plant seeds as bioreactors for recombinant protein production. Biotechnol Adv. 2009;27:1015-22.

59. Fujiki Y, Kudo K, Ono H, Otsuru M, Yamaoka Y, Akita M, Nishida I. Genetic disruption of CRC 12S globulin increases seed oil content and seed yield in Arabidopsis thaliana. Plant Biotechnol. 2013;30:327-33.

60. Baud S, Lepiniec L. Physiological and developmental regulation of seed oil production. Prog Lipid Res. 2010;49:235-49.

61. Hildebrandt Tatjana M, Nunes Nesi A, Araújo Wagner L, Braun H-P. Amino acid catabolism in plants. Mol Plant. 2015;8:1563-79.

62. Pollard M, Martin TM, Shachar-Hill Y. Lipid analysis of developing Camelina sativa seeds and cultured embryos. Phytochemistry. 2015;118:23-32.
63. Weeks DP. Gene editing in polyploid crops: wheat, camelina, canola, potato, cotton, peanut, sugar cane, and citrus. Prog Mol Biol Transl Sci. 2017; 149:65-80

64. Burglin TR, De Robertis EM. The nuclear migration signal of Xenopus laevis nucleoplasmin. EMBO J. 1987;6:2617-25

65. Cong L, Ran FA, Cox D, Lin S, Barretto R, Habib N, Hsu PD, Wu X, Jiang W, Marraffini LA, et al. Multiplex genome engineering using CRISPR/Cas systems. Science. 2013;339:819-23.

66. Nagaya S, Kawamura K, Shinmyo A, Kato K. The HSP terminator of Arabidopsis thaliana increases gene expression in plant cells. Plant Cell Physiol. 2010;51:328-32.

67. Mali P, Yang L, Esvelt KM, Aach J, Guell M, DiCarlo JE, Norville JE, Church GM. RNA-guided human genome engineering via Cas9. Science. 2013;339:823-6.

68. Engler C, Kandzia R, Marillonnet S. A one pot, one step, precision cloning method with high throughput capability. PLoS One. 2008;3:e3647.

69. Rozwadowski K, Yang W, Kagale S. Homologous recombination-mediated cloning and manipulation of genomic DNA regions using gateway and recombineering systems. BMC Biotechnol. 2008;8:88.

70. Weber E, Engler C, Gruetzner R, Werner S, Marillonnet S. A modular cloning system for standardized assembly of multigene constructs. PLoS One. 2011; 6(2):e16765.

71. Sarrion-Perdigones A, Vazquez-Vilar M, Palací J, Castelijns B, Forment J, Ziarsolo P, Blanca J, Granell A, Orzaez D. GoldenBraid 2.0: a comprehensive DNA assembly framework for plant synthetic biology. Plant Physiol. 2013; 162:1618-31.

72. Troëng S. Oil determination of oilseed. Gravimetric routine method. J Am Oil Chem Soc. 1955:32:124-6.

73. Barthet VJ, Daun JK. Oil content analysis: myths and reality. In: Champaign $\mathrm{LDL}$, editor. Oil extraction and analysis: critical issues and comparative studies. Illinois: AOCS Press; 2004. p. 100-17.

74. International A: method 46-18.01. Crude protein, calculated from percentage of total nitrogen, in feeds and feedstuffs. 11th ed. St. Paul, MN: AACC International; 1999.

75. International A: method 994.12. Amino acids in feeds. In: Official methods of analysis. 16th ed. Arlington, VA: AOAC International; 1994.

76. Tuan Y-H, Phillips RD. Optimized determination of cystine/cysteine and acid-stable amino acids from a single hydrolysate of casein- and sorghumbased diet and digesta samples. J Agric Food Chem. 1997;45(9):3535-40.

77. Heydarian Z, Yu M, Gruber M, Glick BR, Zhou R, Hegedus DD. Inoculation of soil with plant growth promoting bacteria producing 1-aminocyclopropane1-carboxylate deaminase or expression of the corresponding acds gene in transgenic plants increases salinity tolerance in Camelina sativa. Front Microbiol. 2016:7:1966.

\section{Publisher's Note}

Springer Nature remains neutral with regard to jurisdictional claims in published maps and institutional affiliations.
Ready to submit your research? Choose BMC and benefit from:

- fast, convenient online submission

- thorough peer review by experienced researchers in your field

- rapid publication on acceptance

- support for research data, including large and complex data types

- gold Open Access which fosters wider collaboration and increased citations

- maximum visibility for your research: over $100 \mathrm{M}$ website views per year

At $\mathrm{BMC}$, research is always in progress.

Learn more biomedcentral.com/submissions 